\title{
Genetic Findings of Sanger and Nanopore Single-Molecule Sequencing in Patients with X-Linked Hearing Loss and Incomplete Partition Type III
}

\author{
Ying Chen \\ Ear Institute, Shanghai Jiaotong University School of Medicine \\ Jiajun Qiu \\ Ear Institute,Shanghai Jiaotong University of Medicine \\ Yingwei Wu \\ Department of Radiology, Shanghai Ninth People's Hospital \\ Huan Jia \\ Ear Institute, Shanghai Jiaotong University School of Medicine \\ Yi Jiang \\ Ear Institute Shanghai Jiaotong University School of Medicine \\ Mengda Jiang \\ Department of Radiology Shanghai Ninth People's Hospital \\ Zhili Wang \\ Ear Institute, Shanghai Jiaotong University School of Medicine \\ Hai-Bin Sheng \\ Ear Institute Shanghai Jiaotong University School of Medicine \\ Lingxiang $\mathrm{Hu}$ \\ Ear Institute Shanghai Jiaotong University School of Medicine \\ Zhihua Zhang \\ Ear Institute Shanghai Jiaotong University School of Medicine \\ Zhaoyan Wang \\ Ear Institute Shanghai Jiaotong University School of Medicine \\ Yun Li \\ Ear Institute Shanghai Jiaotong University School of Medicine \\ Zhiwu Huang \\ Ear Institute Shanghai Jiaotong University School of Medicine \\ HaoWu ( $\square$ wuhao@shsmu.edu.cn) \\ Ear Institute,Shanghai JiaoTong University School of Medicine https://orcid.org/0000-0002-5317-902X
}

Research

Keywords: IP-III, POU3F4, Nanopore single-molecule sequencing, hearing outcomes

Posted Date: May 13th, 2021

DOI: https://doi.org/10.21203/rs.3.rs-501574/v1

License: @ (i) This work is licensed under a Creative Commons Attribution 4.0 International License. Read Full License

Version of Record: A version of this preprint was published at Orphanet Journal of Rare Diseases on February 21st, 2022. See the published version at https://doi.org/10.1186/s13023-022-02235-7. 


\section{Abstract}

Background

POU3F4 is the causative gene for X-linked deafness-2 (DFNX2), characterized by incomplete partition type III (IP-III) malformation of the inner ear. The aim of this study was to investigate the clinical characteristics and molecular findings by Sanger or Nanopore singlemolecule sequencing in IP-III patients.

Methods

Diagnosis of IP-III was mainly based on clinical characteristics including radiological and audiological findings. Sanger sequencing of POU3F4 were carried out for these IP-III patients. For those patients with negative results for POU3F4 Sanger sequencing, Nanopore longread single-molecule sequencing was used to identify the possible pathogenic variants. Hearing intervention outcomes of hearing aids fitting and cochlear implantation were also analyzed. Grouped by different locations of POU3F4 variants, aided PTA was further compared between patients in whom the variants located in the exon region or in the upstream region.

Results

In total, 18 male patients from 14 unrelated families were diagnosed with IP-III. 10 variants were identified in POU3F4 by Sanger sequencing and 9 of these were novel (p.Val321Gly, p.GIn181*, p.Cys233*, p.Val215Gly, p.Arg282GIn, p.Trp57*, p.GIn316*, c.903_912 delins TGCCA and p.Arg205del). Four different deletions (DELs) that varied from 80 to $486 \mathrm{~kb}$ were identified $876-1503 \mathrm{~kb}$ upstream of POU3F4 by Nanopore long-read single-molecule sequencing. Of them, de novo genetic mutations occurred in $21.4 \%$ (3/14) of patients with POU3F4 mutations. Of these 18 patients, 7 had bilateral hearing aids (HAs) and 10 patients received unilateral cochlear implantation $(\mathrm{Cl})$. The mean aided pure tone average (PTA) for HAs and $\mathrm{Cl}$ users were $41.1 \pm 5.18$ and $40.3 \pm 7.59 \mathrm{~dB} \mathrm{HL}$ respectively. The mean PTAs for whom the variants located in the exon and upstream regions were $39.6 \pm 6.31$ vs $43.0 \pm 7.10 \mathrm{~dB} \mathrm{HL}$, which presented no significant difference $(p=0.342)$.

Conclusions

Among IP-III patients, 28.6\% (4/14) had no definite mutation in exon region of POU3F4, however, possible pathogenic deletions were identified in upstream region of this gen. De novo genetic mutations occurred in $21.4 \%(3 / 14)$ of patients with POU3F4 mutation. Hearing intervention outcomes of IP-III patients presented no difference regardless of the variants locations on exon or upstream regions.

\section{Introduction}

Hearing loss is the most common sensory deficit with a prevalence of 1-2 in 1000 newborns [1], and genetic factors account for over $50 \%$ of cases [2]. With respect to genetic hearing loss, deafness is transmitted by an X-linked inheritance pattern in $2-3 \%$ of cases [2,3]. To date, according to the Hereditary Hearing Loss website (http://hereditaryhearingloss.org), six loci (DFNX1-6) and five causative genes have been identified in X-linked hearing loss: PRPS1 (OMIM 311850) for DFNX1, POU3F4 (OMIM 300039) for DFNX2, SMPX (OMIM 300226) for DFNX4, AIFM1 (OMIM 300169) for DFNX5, and COL4L6 (OMIM 303631) for DFNX6.

The most common gene for DFNX is POU3F4, encoding a transcription factor that belongs to the POU-domain family (NM_000307.4) [4, 5]. POU3F4 comprises a POU-specific domain and a POU-homeodomain, both of which influence DNA binding and specificity [6]. POU3F4 is expressed in the developing neural tube, the supraoptic and paraventricular nuclei of the hypothalamus [5, 7], and the inner ear (mainly in the spiral ligament, Reissner's membrane and bony spiral lamina) [8-12], DFNX2 was originally reported in 1971 as an X-linked pattern characterized in males by profound mixed deafness, vestibular abnormalities, and congenital fixation of the stapes with perilymphatic gusher in a Caucasian kindred [13]. In 2002, this type of cochlear abnormality was classified as incomplete partition type III (IP-III) [14]. Previous studies have identified over 90 mutations of POU3F4 related to DFNX2 including missense/nonsense, insertions, deletions, or duplications (The Human Gene Mutation Database, http://www.hgmd.cf.ac.uk). Missense mutations in functional domains might change their structures, abolishing their original roles in cells or inducing endoplasmic reticulum stress [4, 15-17]. Frameshift truncations and extension mutations are also pathogenic as they cause functional deterioration by reducing protein stability and mislocations within the cell [18].

Phenotypically, DFNX2 predominantly manifests in male patients as severe-to-profound mixed hearing loss with cochlear anomalies characteristic of IP-III, dilated basal turn and absent modiolus $[13,14,19]$. Cochlear implantation (CI) is one of the main methods of hearing intervention in this population although it is associated with increased risk of cerebrospinal fluid (CSF) gusher and aberrant 
electrode positioning in the internal auditory canal (IAC) [20]. Furthermore, Cl outcomes were reported to be variable [21-23], probably because the studies were based on limited case series with low patient numbers.

In this study, we report the clinical characteristics and molecular findings by Sanger or Nanopore single-molecule sequencing in IP-III patients resulting from POU3F4 anomalies as well as their hearing intervention outcomes.

\section{Materials And Methods}

\section{Patients}

Between January 2017 and October 2019, 18 male patients from 14 unrelated Chinese families diagnosed with IP-III malformations were recruited in the Department of Otolaryngology-Head and Neck Surgery, Shanghai Ninth People's Hospital Affiliated to Shanghai Jiaotong University School of Medicine. All 18 patients underwent a complete medical history inquiry and gave written, informed consent to participate in this study.

\section{Clinical characteristics}

Auditory evaluations included otoscopic examination, tympanogram, pure tone average (PTA) or auditory brainstem responses (ABR). The degree of hearing impairment was calculated as the average of the hearing levels at 0.5, 1.0, 2.0 and $4.0 \mathrm{kHz}$ for the better ear. The severity of hearing loss was defined as mild (26-40 dB HL), moderate (41-60 dB HL), severe (61-80 dB HL), or profound (>80 dB HL).

Temporal bone high-resolution computed tomography (HRCT) was performed using a 64-section CT scanner (Somatom Definition Flash, Siemens Medical Solutions, Germany). Bone algorithm reconstruction was used for image acquisition. The main parameters for CT scanning were as follows: $120 \mathrm{kV}, 150 \mathrm{mAs}$, and $0.6 \mathrm{~mm}$ section thickness. Cochlea, IAC, vestibule, semicircular canals, vestibular aqueduct, nerve canals in the fundus of the IAC, stapes and cochlear nerves (CN) were rigorously investigated by HRCT.

\section{Hearing interventions and outcome evaluations}

Appropriate hearing interventions and follow-up evaluations were conducted for patients according to their age, level of hearing loss and individual factors. Aided PTA of hearing aid $(\mathrm{HA})$ and $\mathrm{Cl}$ was recorded as hearing outcomes. In cases of $\mathrm{Cl}$, these data were compared with 20 implantees in our center who had normal cochlear structures. The t-test was used to compare the aided PTAs using IBM SPSS Statistics, Version 19.0 (IBM Corp., Armonk, NY, USA). A p-value less than 0.05 was considered indicative of statistical significance and all of the tests were two-tailed.

\section{Genetic analysis}

Genomic DNA was extracted from blood samples using the Blood DNA kit (TIANGEN BIOTECH, Beijing, China). All probands, and other family members where possible, were screened for variants of POU3F4 coding sequences using PCR amplification and bidirectional Sanger sequencing. Possible pathogenic effects of the missense mutations were evaluated using computational tools including Mutation Taster, PROVEAN and SIFT. The allele frequencies of the variants detected were also investigated in 200 Chinese patients with normal hearing. The 3D structures of proteins were modeled using the Swiss-Model website (http://swissmodel.expasy.org) and visualized using RasMol (v. 2.7.5) software.

For those with negative results of POU3F4 Sanger sequencing, Nanopore long-read single-molecule sequencing was used to identify structural variants (SVs). The major types of SV included deletion (DEL), insertion (INS), duplication (DUP), inversion (INV), and translocation (TRA). Further annotation of SVs was performed using ANNOVAR(https://github.com/WGLab/doc-ANNOVAR) combining public databases such as 1000 genome phase3, DGV gold standard CNV, dbVar nstd37, and Decipher.

\section{Results}

\section{Clinical data and hearing phenotypes}

In total, 18 male patients with IP-III malformations were recruited for this study (Fig. 1). The patients were from 14 unrelated Chinese families including thirteen Han and one Zang family (Family 08). The mean age at identification of hearing loss was 1.1 years (range: 0.3-3.6). All patients had bilateral, prelingual, sensorineural or mixed deafness. The results of click-ABR of 14 pediatric patients ranged from 50 to $>97 \mathrm{~dB} \mathrm{nHL}$. With respect to the tympanograms, 67\% (12/18) of them presented a type "A" tympanogram, 17\% (3/18) had type " $C$ ", and 11\% (2/18) presented type "B". Among them, 4 had other problems in addition to hearing loss (Table 1). To note, patient 4 - 
1 was diagnosed with mild autism and had undergone bilateral tympanotomy tube insertion when he was 7 months old to treat "secretory otitis media (SOM)". 
Table 1

Clinical and molecular genetic characteristics of patients with IP-III malformation

\begin{tabular}{|c|c|c|c|c|c|c|c|c|}
\hline Family & Patient & $\begin{array}{l}\text { Age at } \\
\text { detection } \\
\text { (y) }\end{array}$ & $\begin{array}{l}\text { Age } \\
\text { at } \\
\text { visit } \\
\text { (y) }\end{array}$ & $\begin{array}{l}\text { Hearing } \\
\text { loss } \\
\text { level }^{\text {a }}\end{array}$ & Tympanogram & $\begin{array}{l}\text { Other } \\
\text { problems }\end{array}$ & $\begin{array}{l}\text { Hearing } \\
\text { intervention } \\
\text { (side and } \\
\text { age at } \\
\text { which } \mathrm{Cl}^{\mathrm{b}} \\
\text { or } \mathrm{HA}^{\mathrm{c}} \text { was } \\
\text { fitted) }\end{array}$ & POU3F4 variants \\
\hline 01 & 1-1 & 0.5 & 4.2 & $\begin{array}{l}\mathrm{L} 85 ; \mathrm{R} \\
60 \mathrm{~dB} \\
\mathrm{nHL}\end{array}$ & A & / & $\begin{array}{l}\mathrm{HA}(\mathrm{L}+\mathrm{R}, \\
1.7 \mathrm{y})\end{array}$ & c.962T > G (p.Val321Gly) \\
\hline 02 & $2-1$ & 0.4 & 2.4 & $\begin{array}{l}\mathrm{L} 80 ; \mathrm{R} \\
70 \mathrm{~dB} \\
\mathrm{nHL}\end{array}$ & A & / & $\begin{array}{l}\mathrm{Cl}(\mathrm{L}, 4.0 \mathrm{y}) \\
+\mathrm{HA}(\mathrm{R} \\
0.7 \mathrm{y})\end{array}$ & c.541C > T (p.GIn181*) \\
\hline 03 & $3-1$ & 0.4 & 2.3 & $\begin{array}{l}\mathrm{L} 65 ; \mathrm{R} \\
65 \mathrm{~dB} \\
\mathrm{nHL}\end{array}$ & A & & $\begin{array}{l}\mathrm{Cl}(\mathrm{R}, 2.7 \mathrm{y}) \\
+\mathrm{HA} \\
(\mathrm{L}, 0.5 \mathrm{y})\end{array}$ & c.699C > A (p.Cys233*) \\
\hline 04 & $4-1$ & 0.5 & 2.1 & $\begin{array}{l}\mathrm{L}>97 \\
\mathrm{R} 80 \mathrm{~dB} \\
\mathrm{nHL}\end{array}$ & C & Mild autism & $\begin{array}{l}\mathrm{Cl}(\mathrm{L}, 4.5 \mathrm{y}) \\
+\mathrm{HA} \\
(\mathrm{R}, 2.5 \mathrm{y})\end{array}$ & $\begin{array}{l}\text { g.81548899_82006629delins } \\
\text { ACCAATTGGTAGTACAAT }\end{array}$ \\
\hline \multirow[t]{2}{*}{05} & $5-1$ & 0.6 & 3.8 & $\begin{array}{l}\mathrm{L} 60 ; \mathrm{R} \\
65 \mathrm{~dB} \\
\mathrm{nHL}\end{array}$ & A & / & $\begin{array}{l}H A(L+R, \\
3.8 y)\end{array}$ & c.644T > G (p.Val215Gly) \\
\hline & $5-2$ & 3.4 & 23.5 & $\begin{array}{l}\text { L 65; R } \\
67.5 \mathrm{~dB} \\
\mathrm{HL}\end{array}$ & A & / & $\begin{array}{l}\mathrm{HA}(\mathrm{L}+\mathrm{R}, \\
14.0 \mathrm{y})\end{array}$ & c.644T > G (p.Val215Gly) \\
\hline \multirow[t]{2}{*}{06} & $6-1$ & 0.5 & 0.5 & $\begin{array}{l}\mathrm{L}>97 \\
\mathrm{R}>97 \\
\mathrm{~dB} n \mathrm{HL}\end{array}$ & A & / & $\mathrm{Cl}(\mathrm{R}, 1.0 \mathrm{y})$ & g.81806051_82292259del \\
\hline & $6-2$ & 3.6 & 67.2 & $\begin{array}{l}\text { L } 106 \\
\text { R } 107.5 \\
\text { dB HL }\end{array}$ & A & / & None & g.81806051_82292259del \\
\hline 07 & $7-1$ & 0.5 & 2.0 & $\begin{array}{l}\mathrm{L}>97 \\
\mathrm{R}>97 \\
\mathrm{~dB} n \mathrm{~nL}\end{array}$ & & / & $\mathrm{Cl}(\mathrm{R}, 2.5 \mathrm{y})$ & $\begin{array}{l}\text { c.648dupG } \\
\text { (p.Leu217ValfsTer9) }\end{array}$ \\
\hline \multirow[t]{2}{*}{08} & $8-1$ & 3.5 & 14.8 & $\begin{array}{l}\text { L } 115 \\
\text { R } 116 \\
\text { dB HL }\end{array}$ & $\mathrm{C}$ & / & $\begin{array}{l}\mathrm{Cl}(\mathrm{R} \\
15.0 \mathrm{y})\end{array}$ & c.845G > A (p.Arg282GIn) \\
\hline & $8-2$ & 3.0 & 12.0 & $\begin{array}{l}\mathrm{L} \\
107.5 \\
\text { R } 105 \\
\text { dB HL }\end{array}$ & $\mathrm{C}$ & Cataract & $\begin{array}{l}\mathrm{Cl}(\mathrm{R} \\
12.0 \mathrm{y})\end{array}$ & c. $845 \mathrm{G}>\mathrm{A}(\mathrm{p}$. Arg282Gln $)$ \\
\hline 09 & $9-1$ & 0.6 & 0.9 & $\begin{array}{l}\mathrm{L} 70 ; \mathrm{R} \\
>97 \mathrm{~dB} \\
\mathrm{nHL}\end{array}$ & A & $\begin{array}{l}\text { Developmental } \\
\text { retardation }\end{array}$ & $\begin{array}{l}\mathrm{Cl}(\mathrm{R}, 1.2 \mathrm{y}) \\
+\mathrm{HA}(\mathrm{L} \\
0.9 \mathrm{y})\end{array}$ & c. $171 \mathrm{G}>\mathrm{A}\left(\right.$ p.Trp57*) ${ }^{d}$ \\
\hline \multirow[t]{2}{*}{10} & $10-1$ & 0.4 & 2.0 & $\begin{array}{l}\mathrm{L}>97 \\
\mathrm{R}>97 \\
\mathrm{~dB} n \mathrm{HL}\end{array}$ & A & / & $\mathrm{Cl}(\mathrm{R}, 3.0 \mathrm{y})$ & g.81839469_82004841del \\
\hline & $10-2$ & 0.4 & 2.0 & $\begin{array}{l}\mathrm{L}>97 \\
\mathrm{R}>97 \\
\mathrm{~dB} n \mathrm{HL}\end{array}$ & A & / & $\mathrm{Cl}(\mathrm{R}, 2.4 \mathrm{y})$ & g.81839469_82004841del \\
\hline
\end{tabular}

a dB nHL: click-ABR results, dB HL: PTA results.

${ }^{\text {b }} \mathrm{Cl}$ : cochlear implantation. ${ }^{\mathrm{c}} \mathrm{HA}$ : hearing aid.

${ }^{\mathrm{d}}$ De novo mutation. 


\begin{tabular}{|c|c|c|c|c|c|c|c|c|}
\hline Family & Patient & $\begin{array}{l}\text { Age at } \\
\text { detection } \\
\text { (y) }\end{array}$ & $\begin{array}{l}\text { Age } \\
\text { at } \\
\text { visit } \\
\text { (v) }\end{array}$ & $\begin{array}{l}\text { Hearing } \\
\text { loss } \\
\text { level }^{\text {a }}\end{array}$ & Tympanogram & $\begin{array}{l}\text { Other } \\
\text { problems }\end{array}$ & $\begin{array}{l}\text { Hearing } \\
\text { intervention } \\
\text { (side and } \\
\text { age at } \\
\text { which } \mathrm{Cl}^{\mathrm{b}} \\
\text { or } \mathrm{HA}^{\mathrm{c}} \text { was } \\
\text { fitted) }\end{array}$ & POU $3 F 4$ variants \\
\hline 11 & $11-1$ & 0.3 & 0.7 & $\begin{array}{l}\text { L 65; R } \\
60 \mathrm{~dB} \\
\mathrm{nHL}\end{array}$ & A & / & $\begin{array}{l}H A(L+R, \\
0.7 y)\end{array}$ & c. $946 C>T\left(p . G \ln 316^{*}\right)$ \\
\hline 12 & $12-1$ & 0.4 & 0.7 & $\begin{array}{l}\text { L 50; R } \\
55 \mathrm{~dB} \\
\mathrm{nHL}\end{array}$ & B & / & $\begin{array}{l}\mathrm{HA}(\mathrm{L}+\mathrm{R}, \\
1.0 \mathrm{y})\end{array}$ & $\begin{array}{l}\text { c.903_912 delins TGCCA } \\
\text { (p.Lys302AlafsTer25) }\end{array}$ \\
\hline 13 & $13-1$ & 0.3 & 4.5 & $\begin{array}{l}\text { L 75; R } \\
60 \mathrm{~dB} \\
\mathrm{nHL}\end{array}$ & B & / & $\begin{array}{l}\mathrm{HA}(\mathrm{L}+\mathrm{R}, \\
4.5 \mathrm{y})\end{array}$ & $\begin{array}{l}\text { c.614_616delGAA } \\
{\text { (p.Arg205del) }{ }^{d}}^{d}\end{array}$ \\
\hline 14 & $14-1$ & 0.5 & 0.6 & $\begin{array}{l}\text { L 65; R } \\
60 \mathrm{~dB} \\
\mathrm{nHL}\end{array}$ & A & $\begin{array}{l}\text { Atrial septal } \\
\text { defect }\end{array}$ & $\begin{array}{l}H A(L+R, \\
0.6 y)\end{array}$ & g.81807331_81887213del ${ }^{\mathrm{d}}$ \\
\hline \multicolumn{9}{|c|}{ a dB nHL: click-ABR results, dB HL: PTA results. } \\
\hline \multicolumn{9}{|c|}{${ }^{\mathrm{b}} \mathrm{Cl}$ : cochlear implantation. ${ }^{\mathrm{C}} \mathrm{HA}$ : hearing aid. } \\
\hline${ }^{d}$ De $n$ & nutati & & & & & & & \\
\hline
\end{tabular}

Among the mothers of all probands, subject $5-3$ was 47 years of age and reported a history of left myringoplasty about two decades earlier. She presented mixed hearing loss in the left ear ( $P T A=48.75 \mathrm{~dB} \mathrm{HL}$ ) and sensorineural hearing loss in the right ear (PTA $=40 \mathrm{~dB}$ $\mathrm{HL}$ ). Meanwhile, HRCT scans showed unaffected inner ears.

\section{Radiological findings}

The HRCT images of all 18 patients showed typical IP-III anomalies: bilateral and symmetrical malformation, a relatively normal shape of outer coating with absence of cochlear modiolus and bony spiral lamina. There was a direct intercommunication between cochlea and IAC with a "cloudy like" characteristic (Fig. 2a I-III). There was a high jugular bulb in 83.3\% (15/18) of patients (Fig. 2a IV). Stapes abnormalities were present in $11.1 \%(2 / 18)$ of patients and included a thickened stapes footplate and absence of fissula ante fenestram (Fig. 2a V). A vestibular aqueduct was occasionally visible, with a normal shape on axial CT images (Fig. 2a VI). The semicircular canals and vestibular aqueduct shapes were also normal. Postoperative HRCT was performed in six Cl users. As examples, straight electrode arrays were successfully implanted on the right side in patients $7-1$ and $10-2$ (Fig. 2b I-II).

\section{Mutations in POU3F4 gene by Sanger sequencing}

From Sanger sequencing, 12 patients from 10 families had hemizygous variants in POU3F4 (Table 1) including 4 nonsense mutations, 3 missense variants, 2 frame-shift mutations and one indel mutation. Apart from c.648dupG identified in Family-07, the other 9 variants were novel. Besides, two variants p.Trp57* and p.Arg205del were de novo mutations for the patients from Family-09 and - 13 cause their mothers had no variants of POU3F4. All these mutations were not present in 200 normal hearing Chinese controls (150 Han and 50 Zang).

Four nonsense mutations, p.GIn181*, p.Cys233*, p.Trp57* and p.GIn316* were identified in Family-02, $-03,-09$ and -11 , respectively (Fig. 3a). Mutations p.Trp57* and p.Gln181* resulted in the loss of the entire POU-specific (POUs) domain and the POU homeodomain $\left(\mathrm{POU}_{\mathrm{HD}}\right)$. In particular, proband $9-1$ had a de novo p.Trp57* hemizygous mutation. p.Cys233* was located in the POUs domain and p.GIn316* was present in the POU $\mathrm{HD}_{\text {D }}$ Both caused premature termination in POU3F4. These residues are highly conserved in species including primates, mammals and other vertebrates (Fig.S1ab).

Three missense variants p.Val321Gly, p.Val215Gly and p.Arg282GIn were identified in Family-01, -05 and - 08, respectively (Fig. 3a). These residues are also highly conserved in different species (Fig.S1ab). These three variants were predicted to be disease causing and deleterious by the three prediction tools used in this study (Table.S1). 
Two frame-shift mutations c.648dupG and c.903_912 delins TGCCA were identified in Family-07 and - 12, respectively. They caused amino acid mutations of p.Leu217ValfsTer9 and p.Lys302AlafsTer25, respectively (Fig. 3a), and resulted in premature termination of POU3F4.

The indel mutation c.614_616delGAA (p.Arg205del), identified in Family-13, was also a de novo mutation in this study. This residue is also highly conserved in different species (Fig.S1a). The predicted structures of wild-type and mutant proteins were observed and analyzed using RasMol (Fig.S1C).

\section{Deletions identified in upstream of POU3F4 by Nanopore long-read single-molecule sequencing}

Sanger sequencing of POU3F4 was negative in 4 families (Family-04, -06, -10 and - 14), so Nanopore long-read single-molecule sequencing was conducted. A total of $40-50 \mathrm{~Gb}$ of reads with a mean length of $11.6-22 \mathrm{~kb}$ was obtained in each sample with an average coverage of $95.3 \%$, and an average depth of $13-16 \times$ for the whole genome. Four different types of DELs were identified (Fig. 3b). The breakpoint junctions of the DELs were verified by Sanger sequencing and the sequences of primers were listed in Table S2.

In proband $4-1$, we detected a $458 \mathrm{~kb}$ DEL and an 18 bp INS located at ChrX (g.81548899_82006629delinsACCAATTGGTAGTACAAT), approximately $1502 \mathrm{~kb}$ upstream of POU3F4. A total of 7 reads supported the DEL. The breakpoint junction and insertion were successfully sequenced in the proband and his mother (Fig. 3c I).

In proband 6 - 1, we identified a $486 \mathrm{~kb}$ DEL (g.81806051_82292259del), $1217 \mathrm{~kb}$ upstream of POU3F4. A total of 7 reads supported the DEL. The junction was successfully sequenced in the proband, his mother and his grandfather (Fig. $3 \mathrm{c} \mathrm{II).}$

In patient 10 - 1, a $165 \mathrm{~kb}$ DEL (g.81839469_82004841del) was detected, about $1503 \mathrm{~kb}$ upstream of the POU3F4 gene. A total of 8 reads supported the DEL. The junction sequence was successfully amplified for the proband, his twin brother and their mother (Fig. $3 \mathrm{c}$ III).

In proband $14-1$, we detected a $80 \mathrm{~kb}$ DEL (g.81807331_81887213del), $876 \mathrm{~kb}$ upstream of the POU3F4 gene, and this mutation was successfully sequenced (Fig. 3c IV). His mother's genotype was normal. The proband had a de novo DEL located upstream of POU3F4.

\section{Effect of hearing intervention and its correlation with genotypes}

Appropriate hearing intervention was carried out in $94.4 \%$ (17/18) of patients in this study. Ten patients received unilateral $\mathrm{Cl}$ with or without HA on the contralateral side. Seven patients wore bilateral HAs. Only one patient did not receive hearing intervention: Patient 6 2, 67 years of age, had congenital hearing loss, never had a HA and used sign language in daily life.

For $10 \mathrm{Cl}$ users, mean aided PTA was $40.3 \pm 7.59 \mathrm{~dB} \mathrm{HL}$ (range: $25.0-51.3 \mathrm{~dB} \mathrm{HL}$ ) 12 months after activation of the implant. Compared with the control group (age-matched $\mathrm{Cl}$ recipients with normal cochlea, $\mathrm{N}=20, \mathrm{PTA}=34.0 \pm 5.74 \mathrm{~dB} \mathrm{HL}$ ), the result was not statistically different $(p=0.20)$. The genotypes of these IP-III patients consisted of 3 nonsense mutations (p.GIn181*, p.Cys233*, p.Trp57*), one frame-shift mutation (c.648dupG), one missense variant (p.Arg282GIn) and 3 upstream DELs (165-486 kb).

For 7 patients with bilateral HAs, mean aided PTA of the better ear was $41.1 \pm 5.18 \mathrm{~dB} \mathrm{HL}$ (range: 35.0-50.0 dB HL). The genotypes of them were p.Val215Gly (two siblings), p.Val321Gly, p.Arg205del, c.903_912 delins TGCCA, p.Gln316* and g.81807331_81887213del (80 $\mathrm{kb}$ DEL).

Based on the location of variants, 17 patients with $\mathrm{HAs}$ or $\mathrm{Cl}$ were further divided into two groups: variants located in the exon region of POU3F4 (ER group, $\mathrm{N}=12$ ) or the upstream region (UR group, $\mathrm{N}=5$ ). Mean aided PTA of the ER group was $39.6 \pm 6.31 \mathrm{~dB} H \mathrm{H}$, and that of the UR group was $43.0 \pm 7.10 \mathrm{~dB} \mathrm{HL}$. The difference was not significant $(p=0.342)$.

\section{Discussion}

In this study, we analyzed the clinical characteristics, molecular variants and hearing intervention outcomes in 18 patients with IP-III from 14 unrelated families. To the best of our knowledge, the largest cohort with IP-III in previous studies was 11 cases [24]. Ten different variants were identified in the exon region of POU3F4, of which nine were novel. Four novel DELs in the upstream region of POU3F4 were identified by Nanopore long-read single-molecule sequencing. For the first time, this study also measured the hearing outcomes of IP-III patients grouped by different locations of variants in POU3F4.

For the clinical diagnosis of IP-III, it is difficult to predict IP-III malformation merely from the family history and audiological outcomes. In this study, 8 of 14 (57.1\%) IP-III families contained sporadic cases and the level of hearing loss varied greatly. HRCT of temporal bone 
appears to be more reliable for predicting POU3F4 variants and is essential for IP-III diagnosis. HRCT images showed typical characteristic "cloudy like" anomalies: a relatively normal shape of outer coating, and direct intercommunication between the cochlea and IAC. Incomplete partitions occurred in $41 \%$ of inner ear malformations and IP-III constituted $2 \%$ of malformations in this region [4]. To note, HRCT examination is strongly recommended before invasive hearing intervention in children with mixed hearing loss. In this study, one patient was misdiagnosed with SOM as he did not undergo a CT scan before bilateral tympanotomy tube insertion.

$71.4 \%(10 / 14)$ of unrelated IP-III patients had hemizygous variants in the exon region of POU3F4 based on Sanger sequencing in this study. 28.6\% (4/14) patients had 80-486 kb DELs upstream of POU3F4 using Nanopore long-read single-molecule sequencing. In previous studies, DELs identified upstream of POU3F4 varied from $2.6 \mathrm{~kb}$ to $1.75 \mathrm{Mb}[25,26]$. Entire deletions, insertions and translocations of POU3F4 were also recognized to be pathogenic in some cases $[25,27-29]$. The DELs upstream of POU3F4 were also located downstream of $S H 3 B G R L$. SH3BGRL was reported to play a role in gastric cancer, acute myeloid leukemia and breast cancer [3032]. However, whether DELs located between POU3F4 and SH3BGRL genes influence the function of SH3BGRL remains unknown.

Besides, $21.4 \%$ (3/14) de novo mutations of POU3F4 were found including two mutations located in the exon region and one located in the upstream region. In a previous study, de novo genetic mutations occurred in $20 \%$ of patients with POU3F4 mutations [27]. These results indicate that the high rate of de novo mutations is one reason for the relatively high incidence of sporadic cases of POU3F4 variants. To note, two probands with de novo mutations located in the exon region (p.Trp57* and p.Arg205del) presented relatively asymmetric hearing loss (interaural threshold gap $\geq 15 \mathrm{~dB} \mathrm{nHL}$ ).

Hearing intervention ouctomes were reported to vary greatly among IP-III patients [16, 25]. Stankovic et al reported limited auditory perception and language acquisition after $\mathrm{Cl}$ in IP-III patients and commented that $\mathrm{HA}$ may sometimes be a better alternative than $\mathrm{Cl}$ [23]. In our study, aided PTA values in HA users and $\mathrm{Cl}$ recipients were $41.1 \pm 5.18 \mathrm{~dB} \mathrm{HL}$ and $40.3 \pm 7.59 \mathrm{~dB} \mathrm{HL}$, respectively. These results showed that $\mathrm{Cl}$ was also an optimal intervention method for IP-III patients. This study firstly focused on the correlation of genotype and hearing outcomes based on the variants locations. As a result, the aided PTA presented no difference regardless of the variants locations on exon or upstream regions $(p=0.342)$.

This study has three potential limitations. The first is the short follow-up period of 12 months for hearing outcomes. Long-term follow-up is still needed. The second limitation is the uncertainty over the pathogenicity of variants, especially DELs identified in the upstream region of POU3F4. Further functional studies are required at the animal level to obtain clear evidence. The final limitation of this study is the lack of sensitive indicators to predict outcomes of hearing intervention in IP-III patients. The benefits of $\mathrm{Cl}$ vary greatly among individual patients $[23,24,33]$. It has also been demonstrated that the number and capability of spiral ganglion neurons (SGNs) are important factors for $\mathrm{Cl}$ outcomes [34-36]. Animal studies have shown that radial bundle fasciculation and hair cell innervation of SGNs were impaired after Pou3f4 was deleted from the otic mesenchyme [34]. A recent animal study verified that, with the absence of the mesenchyme-specific transcription factor Pou3f4, a portion of SGNs underwent apoptosis after birth resulting in an approximately $25 \%$ decrease in the overall SGN population [37]. Whether there is a neurophysiological or other indicator which might provide clinical prediction of the function of SGNs and Cl outcomes is still unknown.

In conclusion, $28.6 \%(4 / 14)$ had no mutation in exon region of POU3F4, however, possible pathogenic deletions were identified in upstream region of this gene. De novo genetic mutations occurred in $21.4 \%(3 / 14)$ of patients with POU3F4 mutation. Hearing intervention outcomes of IP-III patients presented no difference regardless of the variants locations on exon or upstream regions.

\section{Abbreviations}

IP-III: incomplete partition type III; DELs: deletions; PTA: pure tone average; Cl: cochlear implantation; CSF: cerebrospinal fluid; IAC: internal auditory canal; HRCT: high-resolution computed tomography; CN: cochlear nerves; ABR: auditory brainstem responses; IT-MAIS: infanttoddler meaningful auditory integration scale; CAP: categories of auditory performance; MUSS: meaningful use of speech scale; SIR: speech intelligibility rating; SV: structural variants; INS: insertion; DUP: duplication; INV: inversion; TRA: translocation; SOM: secretory otitis media; NHS: newborn hearing screening; CISS: constructive interference in steady-state; HA: hearing aid; ER: exon region; UR: upstream region

\section{Declarations}

\section{Ethics approval and consent to participate}


All participants gave written, informed consent to participate in this study. The study was approved by the Ethics Committee of the Ninth People's Hospital, Shanghai Jiaotong University School of Medicine (No. SH9H-2019-T245-1).

\section{Consent for publication}

A consent for publication has been obtained.

\section{Availability of data and materials}

Please contact author for data requests.

\section{Competing interests}

The authors declare that they have no competing interests.

\section{Fundings}

This research was supported by grants from the National Natural Science Foundation of China (81730028 to HW and 81800899 to YC), Clinical Research Plan of SHDC (SHDC2020CR1044B to HW), Shanghai "Rising Stars of Medical Talent" Youth Development Program (Youth Medical Talents - Specialist Program to YC), SHIPM-mu fund from Shanghai Institute of Precision Medicine, Ninth People's Hospital Shanghai Jiao Tong University School of Medicine (JC201802 to YC)

\section{Authors' contributions}

$\mathrm{HW}, \mathrm{ZWH}$ and $\mathrm{YL}$ designed the research; $\mathrm{YC}$ analyzed the data and wrote the manuscript; $Y C$ and QJJ performed genotyping and analyzed the data; YC, YWW, MDJ, JJQ, ZLW, JY and HBS participated in phenotyping and clinical data collection; HW, ZYW, ZHZ, HJ and $\mathrm{LXH}$ performed surgery. All authors read and approved the final manuscript.

\section{Acknowledgements}

Thanks are due to Professor Olivier Sterkers, Dr Sheng-long Qiao and Alpha Science Editors for valuable discussion and language editing.

\section{References}

1. Berninger E, Westling B. Outcome of a universal newborn hearing-screening programme based on multiple transient-evoked otoacoustic emissions and clinical brainstem response audiometry. Acta Otolaryngol. 2011;131(7):728-39.

2. Morton NE. Genetic epidemiology of hearing impairment. Ann N Y Acad Sci. 1991; 630:16-31.

3. Marazita ML, Ploughman LM, Rawlings B, Remington E, Arnos KS, Nance WE. Genetic epidemiological studies of early-onset deafness in the U.S. school-age population. Am J Med Genet. 1993;46(5):486-91.

4. de Kok YJ, van der Maarel SM, Bitner-Glindzicz M, Huber I, Monaco AP, Malcolm S, Pembrey ME, Ropers HH, Cremers FP. Association between X-linked mixed deafness and mutations in the POU domain gene POU3F4. Science. 1995;267(5198):685-8.

5. Mathis JM, Simmons DM, He X, Swanson LW, Rosenfeld MG. Brain 4: a novel mammalian POU domain transcription factor exhibiting restricted brain-specific expression. EMBO J. 1992; 11(7):2551-61.

6. Bademci G, Lasisi A, Yariz KO, Montenegro P, Menendez I, Vinueza R, Paredes R, Moreta G, Subasioglu A, Blanton S, et al. Novel domain-specific POU3F4 mutations are associated with X-linked deafness: examples from different populations. BMC Med Genet. 2015;16:9.

7. Le Moine C, Young WS, 3rd. RHS2, a POU domain-containing gene, and its expression in developing and adult rat. Proc Natl Acad Sci U S A. 1992;89(8):3285-9.

8. Dominov JA, Miller JB. POU homeodomain genes and myogenesis. Dev Genet. 1996; 19(2):108-18.

9. Hussain MA, Lee J, Miller CP, Habener JF. POU domain transcription factor brain 4 confers pancreatic alpha-cell-specific expression of the proglucagon gene through interaction with a novel proximal promoter G1 element. Mol Cell Biol. 1997;17(12):7186-94.

10. Phippard D, Heydemann A, Lechner M, Lu L, Lee D, Kyin T, Crenshaw EB, 3rd. Changes in the subcellular localization of the Brn4 gene product precede mesenchymal remodeling of the otic capsule. Hear Res. 1998;120(1-2):77-85.

11. Phippard D, Lu L, Lee D, Saunders JC, Crenshaw EB, 3rd. Targeted mutagenesis of the PoU-domain gene Brn4/Pou3f4 causes developmental defects in the inner ear. J Neurosci. 1999;19(14):5980-9. 
12. Arellano B, Ramirez Camacho R, Garcia Berrocal JR, Villamar M, del Castillo I, Moreno F. Sensorineural hearing loss and Mondini dysplasia caused by a deletion at locus DFN3. Arch Otolaryngol Head Neck Surg. 2000;126(9):1065-9.

13. Nance WE, Setleff R, McLeod A, Sweeney A, Cooper C, McConnell F. X-linked mixed deafness with congenital fixation of the stapedial footplate and perilymphatic gusher. Birth Defects Orig Artic Ser. 1971;07(4):64-9.

14. Sennaroglu L, Saatci I. A new classification for cochleovestibular malformations. Laryngoscope. 2002;112(12):2230-41.

15. Bitner-Glindzicz M, Turnpenny P, Hoglund P, Kaariainen H, Sankila EM, van der Maarel SM, de Kok YJ, Ropers HH, Cremers FP, Pembrey M, et al. Further mutations in Brain 4 (POU3F4) clarify the phenotype in the X-linked deafness, DFN3. Hum Mol Genet. 1995; 4(8):1467-9.

16. Lee HK, Song MH, Kang M, Lee JT, Kong KA, Choi SJ, Lee KY, Venselaar H, Vriend G, Lee WS, et al. Clinical and molecular characterizations of novel POU3F4 mutations reveal that DFN3 is due to null function of POU3F4 protein. Physiol Genomics. 2009;39(3):195-201.

17. Datta R, Waheed A, Bonapace G, Shah GN, Sly WS. Pathogenesis of retinitis pigmentosa associated with apoptosis-inducing mutations in carbonic anhydrase IV. Proc Natl Acad Sci U S A. 2009;106(9):3437-42.

18. Choi BY, Kim DH, Chung T, Chang M, Kim EH, Kim AR, Seok J, Chang SO, Bok J, Kim D, et al. Destabilization and mislocalization of POU3F4 by C-terminal frameshift truncation and extension mutation. Hum Mutat. 2013;34(2):309-16.

19. Sennaroglu L, Bajin MD. Classification and Current Management of Inner Ear Malformations. Balkan Med J. 2017;34(5):397-411.

20. Sennaroglu L, Bajin MD. Incomplete partition type III: A rare and difficult cochlear implant surgical indication. Auris Nasus Larynx. 2018;45(1):26-32.

21. Smeds H, Wales J, Asp F, Lofkvist U, Falahat B, Anderlid BM, Anmyr L, Karltorp E. X-linked Malformation and Cochlear Implantation. Otol Neurotol. 2017;38(1):38-46.

22. Lee HK, Lee SH, Lee KY, Lim EJ, Choi SY, Park RK, Kim UK. Novel POU3F4 mutations and clinical features of DFN3 patients with cochlear implants. Clin Genet. 2009;75(6):572-5.

23. Stankovic KM, Hennessey AM, Herrmann B, Mankarious LA. Cochlear implantation in children with congenital X-linked deafness due to novel mutations in POU3F4 gene. Ann Otol Rhinol Laryngol. 2010;119(12):815-22.

24. Choi BY, An YH, Song JJ, Koo JW, Lee JH, Oh SH, Chang SO, Kim CS, Park JH. Clinical observations and molecular variables of patients with hearing loss and incomplete partition type III. Laryngoscope. 2016;126(3):E123-8.

25. de Kok YJ, Vossenaar ER, Cremers CW, Dahl N, Laporte J, Hu LJ, Lacombe D, Fischel-Ghodsian N, Friedman RA, Parnes LS, et al. Identification of a hot spot for microdeletions in patients with X-linked deafness type 3 (DFN3) 900 kb proximal to the DFN3 gene POU3F4. Hum Mol Genet. 1996;5(9):1229-35.

26. Choi BY, An YH, Park JH, Jang JH, Chung HC, Kim AR, Lee JH, Kim CS, Oh SH, Chang SO. Audiological and surgical evidence for the presence of a third window effect for the conductive hearing loss in DFNX2 deafness irrespective of types of mutations. Eur Arch Otorhinolaryngol. 2013;270(12):3057-62.

27. Choi JW, Min B, Kim A, Koo JW, Kim CS, Park WY, Chung J, Kim V, Ryu YJ, Kim SH, et al. De novo large genomic deletions involving POU3F4 in incomplete partition type III inner ear anomaly in East Asian populations and implications for genetic counseling. Otol Neurotol. 2015;36(1):184-90.

28. Anger GJ, Crocker S, McKenzie K, Brown KK, Morton CC, Harrison K, MacKenzie JJ. X-linked deafness-2 (DFNX2) phenotype associated with a paracentric inversion upstream of POU3F4. Am J Audiol. 2014;23(1):1-6.

29. Aristidou C, Theodosiou A, Bak M, Mehrjouy MM, Constantinou E, Alexandrou A, Papaevripidou I, Christophidou-Anastasiadou V, Skordis N, Kitsiou-Tzeli S, et al. Position effect, cryptic complexity, and direct gene disruption as disease mechanisms in de novo apparently balanced translocation cases. PLoS One. 2018;13:e0205298.

30. Xiang Z, Huang X, Wang J, Zhang J, Ji J, Yan R, Zhu Z, Cai W, Yu Y. Cross-Database Analysis Reveals Sensitive Biomarkers for Combined Therapy for ERBB2+ Gastric Cancer. Front Pharmacol. 2018;9:861.

31. Li H, Zhang M, Wei Y, Haider F, Lin Y, Guan W, Liu Y, Zhang S, Yuan R, Yang X, et al. SH3BGRL confers innate drug resistance in breast cancer by stabilizing HER2 activation on cell membrane. J Exp Clin Cancer Res. 2020;39(1):81.

32. Xu L, Zhang M, Li H, Guan W, Liu B, Liu F, Wang H, Li J, Yang S, Tong X, Wang H. SH3BGRL as a novel prognostic biomarker is downregulated in acute myeloid leukemia. Leuk Lymphoma. 2018;59(4):918-30.

33. Kim L, Wisely CE, Lucius S, Weingarten J, Dodson EE. Positive Outcomes and Surgical Strategies for Bilateral Cochlear Implantation in a Child With X-Linked Deafness. Ann Otol Rhinol Laryngol. 2016;125(2):173-6. 
34. Coate TM, Raft S, Zhao X, Ryan AK, Crenshaw EB, 3rd, Kelley MW. Otic mesenchyme cells regulate spiral ganglion axon fasciculation through a Pou3f4/EphA4 signaling pathway. Neuron. 2012;73(1):49-63.

35. He S, Shahsavarani BS, McFayden TC, Wang H, Gill KE, Xu L, Chao X, Luo J, Wang R, He N. Responsiveness of the Electrically Stimulated Cochlear Nerve in Children With Cochlear Nerve Deficiency. Ear Hear. 2018;39(2):238-50.

36. Pfingst BE, Hughes AP, Colesa DJ, Watts MM, Strahl SB, Raphael Y. Insertion trauma and recovery of function after cochlear implantation: Evidence from objective functional measures. Hear Res. 2015;330(Pt A):98-105.

37. Brooks PM, Rose KP, MacRae ML, Rangoussis KM, Gurjar M, Hertzano R, Coate TM. Pou3f4-expressing otic mesenchyme cells promote spiral ganglion neuron survival in the postnatal mouse cochlea. J Comp Neurol. 2020;528(12):1967-85.

\section{Figures}
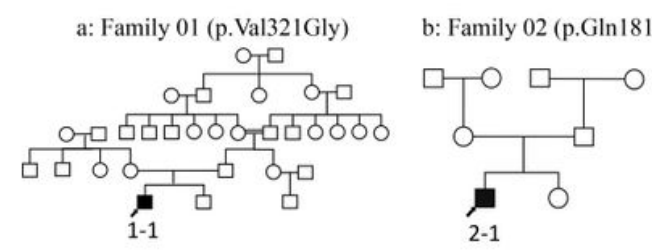

c: Family 03 (p.Cys233*)

d: Family 04 (g.81548899 82006629delins18)

e: Family 05 (p.Val215Gly)

f: Family 06 (g.81806051_82292259del)
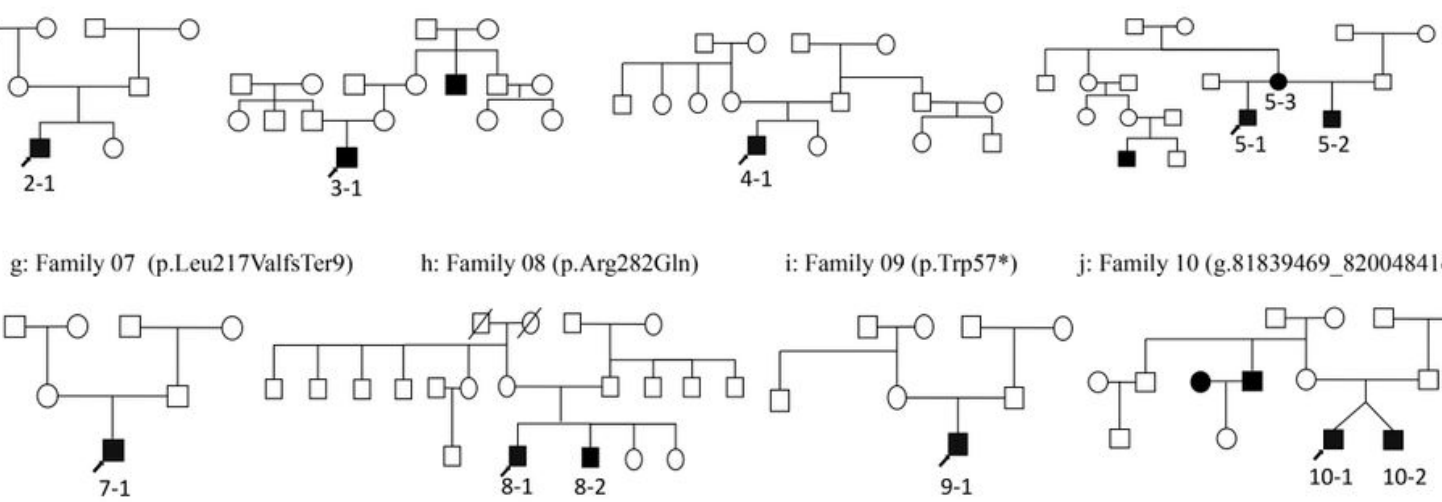

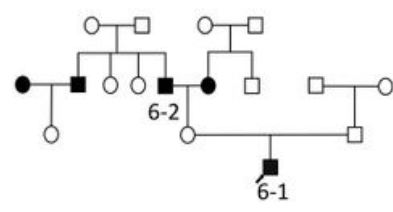

k: Family 11 (p.GIn316*)

I: Family 12 (p.Lys302AlafsTer25)
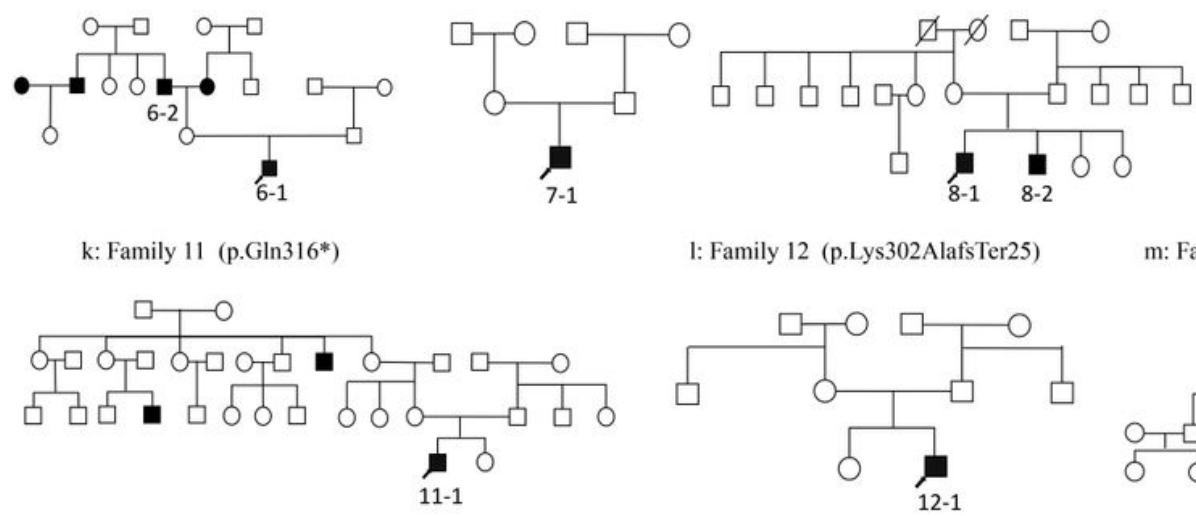

i: Family 09 (p.Trp57*)

j: Family 10 (g.81839469_82004841del)
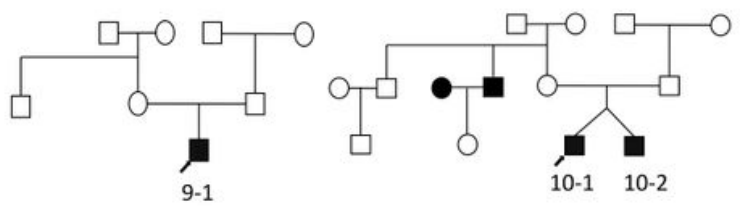

m: Family 13 (p.Arg205del)

n: Family 14 (g.81807331_81887213del)
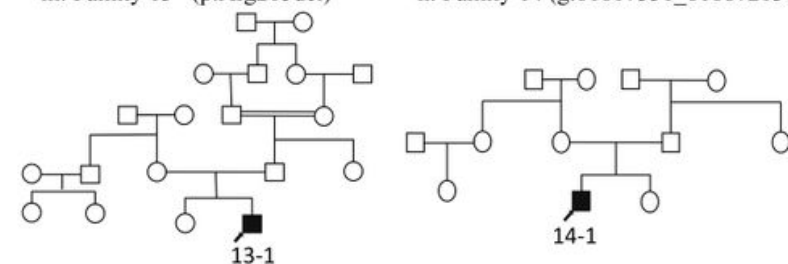

\section{Figure 1}

Pedigrees of the 14 unrelated families Among them, 18 patients diagnosed with IP-III were enrolled in this study and they were numbered from 1-1 to 14-1. 
a: HRCT images from some patients showing IP-III malformations
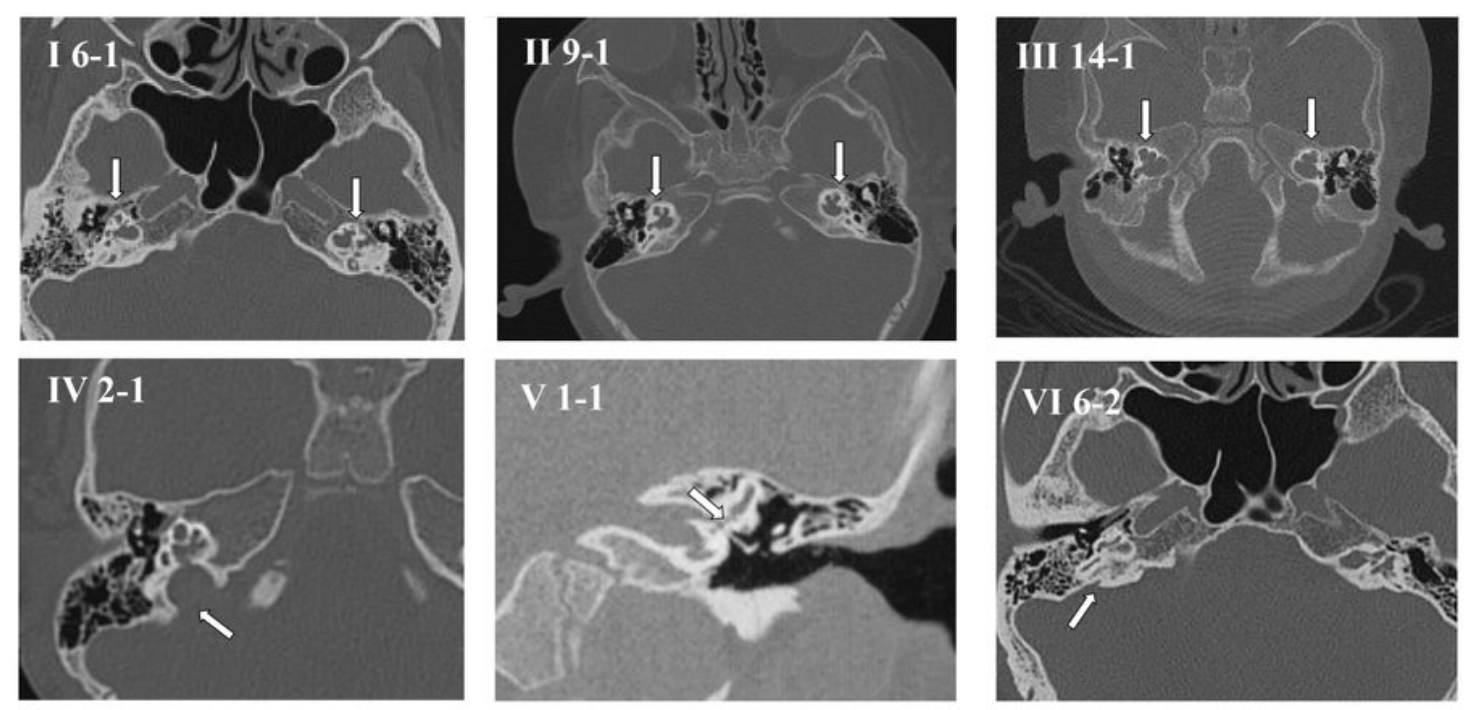

\section{b: HRCT of CI patients showing position of electrodes}
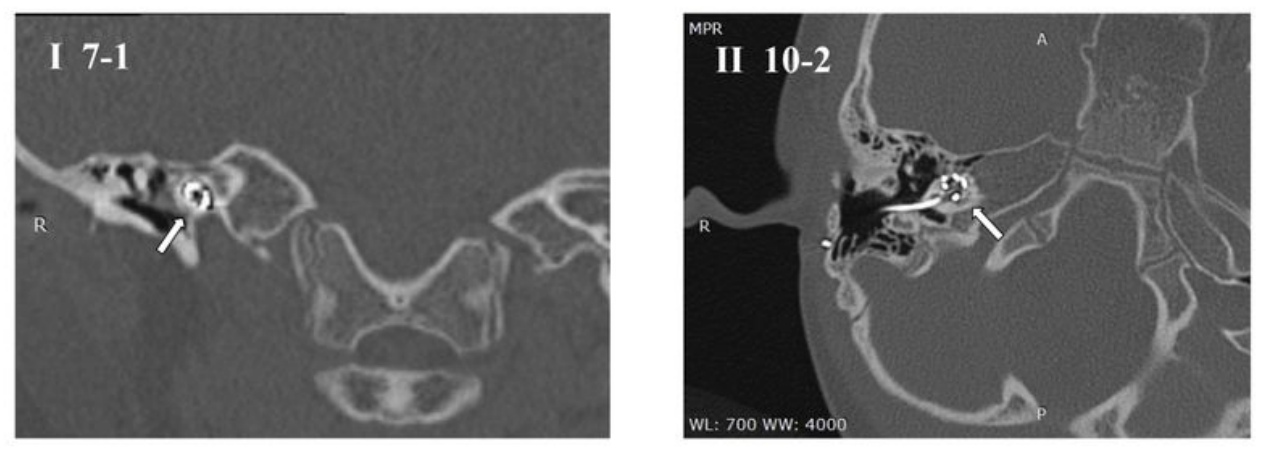

\section{Figure 2}

HRCT images of temporal bone and MRI of inner ear in some IP-III patients (a) HRCT images from some patients showing IP-III malformations. I-III: "Cloudy like" characteristics of the cochlea: absence of cochlear modiolus and bony spiral lamina, and direct intercommunication between cochlea and IAC; IV: High jugular bulb; VIII-IX: Thickened stapes footplate; V: Visible vestibular aqueduct. (b) HRCT of $\mathrm{Cl}$ patients showing position of electrodes. I: Coronal scan of patient 7-1; II: Axial scan of patient 10-2. 
a: Schematic illustration of the exon region of POU3F4 with mutations labeled

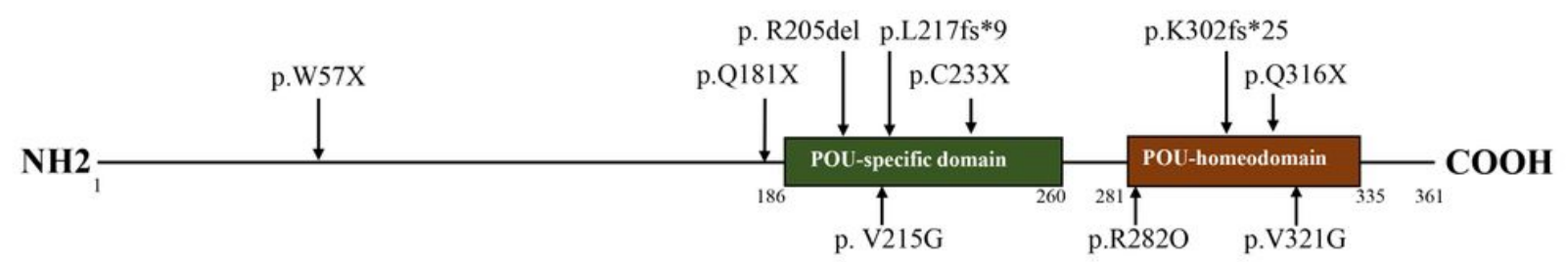

b: Schematic illustration of the upstream region of POU3F4 with DELs indicated

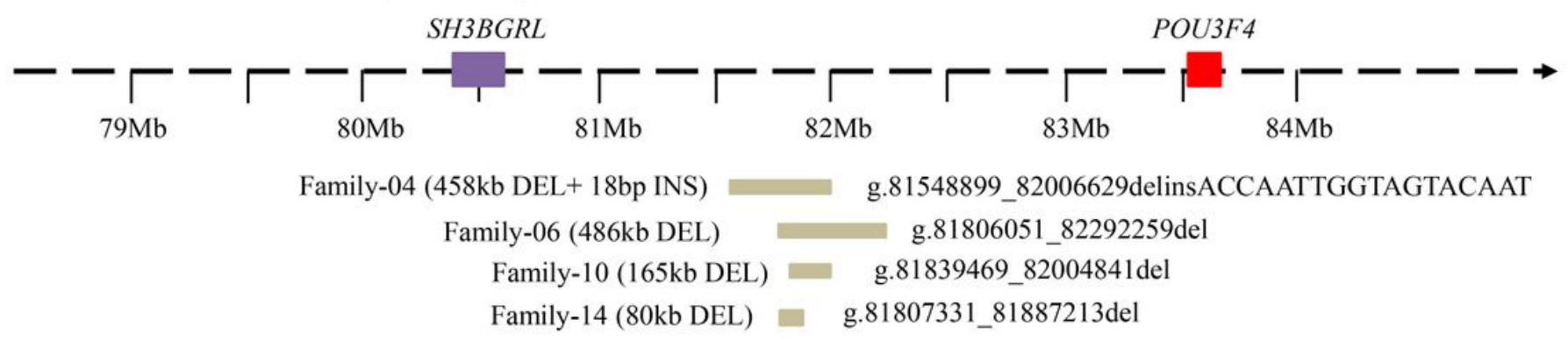

c: The breakpoint junction sequence of families with DELs upstream of POU3F4

I: Family-04

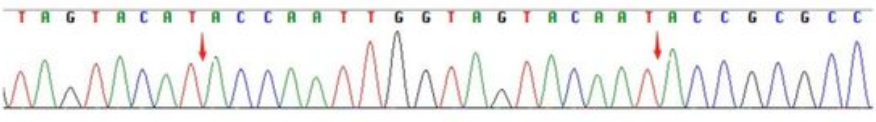

III: Family-10

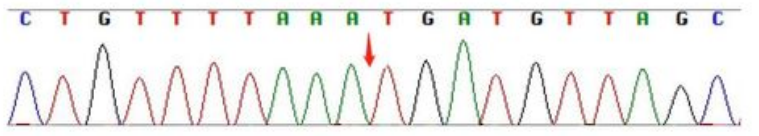

II: Family-06

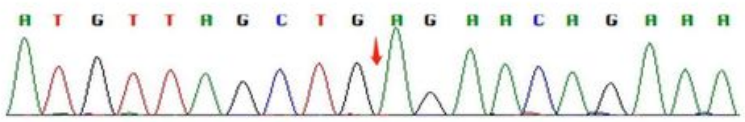

IV: Family-14

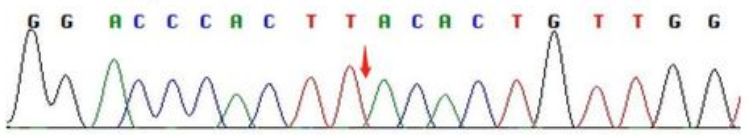

\section{Figure 3}

Identification of POU3F4 variants by Sanger sequencing and Nanopore long-read single-molecule sequencing (a) Schematic illustration of the exon region of POU3F4 with mutations labeled. Four nonsense mutations, three missense variants, two frame-shift mutations and one indel mutation were identified. (b) Schematic illustration of the upstream region of POU3F4 with DELs indicated. These DELs were located between SH3BGRL and POU3F4 genes on the X chromosome. Four DELs varied from 80 to $486 \mathrm{~kb}$. (c) The breakpoint junction sequence of families with DELs upstream of POU3F4. The red arrows indicate the breakpoints. An INS of 18 bp was also identified in Family-04.

\section{Supplementary Files}

This is a list of supplementary files associated with this preprint. Click to download.

- SupplemantaryFigureS12156.pdf

- TableS1.docx

- Tables2.docx 